\section{Sequentially Reducing Sulfate Fertility During Onion Growth and Development Affects Bulb Flavor at Harvest}

\author{
William M. Randle, David E. Kopsell, and Dean A. Kopsell \\ Department of Horticulture, 1111 Plant Sciences Building, University of \\ Georgia, Athens, GA 30602-7273
}

Additional index words. pyruvic acid, $S$-alk(en)yl cysteine sulfoxide, soluble solids content, Allium cepa

\begin{abstract}
A major decision in producing onions with mild flavor on low sulfur soils is determining when to stop applying $\mathrm{SO}_{4}^{-2}$ to the crop. Sulfate $\left(\mathrm{SO}_{4}^{-2}\right)$ is necessary for good early growth, but high levels of available $\mathrm{SO}_{4}^{-2}$ late in the season increase bulb pungency. The objective of this research was to determine how sequentially reducing the availability of $\mathrm{SO}_{4}^{-2}$ during onion growth and development would affect flavor intensity and quality of Granex-type onions. Starting 77 days before harvest, $\mathrm{SO}_{4}{ }^{-2}$ concentrations were lowered from $1 \mathrm{~mm}$ to $0.05 \mathrm{~mm}$ on different blocks of onions in a greenhouse experiment at bi-weekly intervals. Total leaf and bulb $S$ were measured at harvest to monitor $S$ accumulation as $\mathrm{SO}_{4}{ }^{-2}$ fertility was sequentially reduced. Bulbs were harvested and analyzed for flavor precursors and their biosynthetic intermediates, gross flavor intensity as measured by enzymatically developed pyruvic acid (EPY), and soluble solids content. $\mathrm{As} \mathrm{SO}_{4}^{-2}$ fertility reductions were delayed during the experiment, total leaf and bulb $\mathrm{S}$ increased linearly. In addition, bulb EPY concentrations increased linearly as $\mathrm{SO}_{4}^{-2}$ reduction was delayed, indicating increases in overall flavor intensity. While the total concentration of flavor precursors did not significantly change in response to lowering $\mathrm{SO}_{4}^{-2}$ fertility during the experiment, the concentrations of MCSO to 1-PRENCSO did. MCSO concentration decreased and then increased in a quadratic manner. MCSO produces fresh onion and cabbage like flavors. 1-PRENCSO, on the other hand, increased linearly as the high $\mathrm{SO}_{4}^{-}$ ${ }^{2}$ fertility level was extended through bulb maturation. Increasing concentrations of 1PRENCSO causes onions to have significantly more heat and mouth burn when eaten. Reducing available $\mathrm{SO}_{4}{ }^{-2} 49$ days prior to harvest coincided with a reduction in EPY and a change in the flavor biosynthetic pathway that appeared to be associated with the metabolic changes occurring with the onset of bulbing. Chemical names used: enzymatically developed pyruvic acid (EPY); methyl cysteine sulfoxide (MCSO); 1-propenyl cysteine sulfoxide (1-PRENCSO).
\end{abstract}

Onion (Allium cepa L.) flavor is dominated by a special class of sulfur $(\mathrm{S})$ precursor compounds, collectively known as $S$-alk(en)yl cysteine sulfoxides (ACSO) (Block, 1992). Upon maceration of the tissues, alliinase decomposes the ACSOs to form the lachrymatory factor (LF) and thiosulfinates that are responsible for the flavor attributes of cut onions (Randle, 1997). The thiosulfinates are unstable and randomly rearrange and dissociate over time forming other compounds, thereby affecting a time sensitive change in cut onion flavor. The three precursors that give onions their characteristic flavors and aromas are 1-PRENCSO, MCSO, and propyl cysteine sulfoxide (PCSO) (Block, 1992).

Up until the 1990s, onion flavor was reported to be dominated by the accumulation of 1-PRENCSO, which upon decomposition, gives rise to the LF and heat and mouth burn attributes (Block, 1992). MCSO and PCSO were reported to accumulate in lesser concentrations and upon decomposition, gave rise to fresh onion, sul-

Received for publication 22 Jan. 2001. Accepted for publication 1 May 2001 fureous, and cabbage-like attributes. In the 1990 s, research identified several mineral elements that affected the composition and concentration of the individual ACSOs. First, $\mathrm{SO}_{4}{ }^{-2}$ fertility levels dramatically affected the concentration and composition of the ACSOs (Randle et al., 1995). With high $\mathrm{SO}_{4}^{-2}$ fertility, 1-PRENCSO accumulated in highest concentration. However, as $\mathrm{SO}_{4}^{-2}$ fertility incrementally decreased to a level that produced $\mathrm{S}$ deficiency symptoms in the plants, MCSO increased in concentration relative to 1-PRENCSO, and became the dominant precursor at the lower $\mathrm{SO}_{4}^{-2}$ fertility levels. Second, when onions were grown under high sodium selenate $\left(\mathrm{Na}_{2} \mathrm{SeO}_{4}\right)$ fertility levels, MCSO became the dominant precursor (Kopsell and Randle, 1999). This response mimicked the low $\mathrm{SO}_{4}^{-2}$ fertility response and hinted to the competitive nature of $\mathrm{S}$ and $\mathrm{Se}$ in plant metabolism. And third, when onions were grown with luxuriant levels of nitrogen, MCSO accumulated in highest concentration of the three ACSOs (Randle, 2000). These experiments demonstrated that fertility impacted onion flavor intensity and quality. It is the accumulation pattern of the three individual
ACSOs that give rise to differences in onion flavor intensity and quality (Randle, 1997).

The goal for quality onion production is to gradually deplete nutrients, especially $\mathrm{N}$, from soils during advanced bulbing (Brewster, 1990). In doing so, bulbs mature properly and are able to better withstand postharvest handling and storage. For over-wintered mild onions produced on sandy loam soils, applications of Scontaining fertilizers are discouraged after early spring (Vavrina and Granberry, 1988). High amounts of $S$ applied before planting caused S to be available at high levels late in the season, and onions intended to be mild were pungent (Smittle, 1984). Mild onions can be produced by depleting $\mathrm{S}$ from the soils before high levels of ACSOs are synthesized in the leaves and translocated to the swelling bulbs (Lancaster and Boland, 1990; Randle et al., 1993). Liberal applications of $\mathrm{S}$ in the early stages of onion growth and development, however, are required to support good root and foliar growth that positively influence bulb yields. Restricting $\mathrm{SO}_{4}^{-2}$ availability to the plant early in growth and development reduced bulb fresh weight (Randle et al., 1995). Scheduling the reduction of $\mathrm{S}$ from the growing environment is a key management decision by mild onion producers. The object of this research was to determine how sequentially reducing the availability of $\mathrm{SO}_{4}^{-2}$ during onion growth and development would affect flavor intensity and quality in Granex-type onions.

\section{Materials and Methods}

Seeds of 'Sweet Vidalia' (Granex-type, Rio Colorado Seed, Yuma, Ariz.) were planted 3 Oct. 1997 in flats containing Fafard No. 3 (Fafard Co., Anderson, S.C.) artificial medium and greenhouse grown under $28^{\circ} \mathrm{C}$ day/ $16^{\circ} \mathrm{C}$ night temperatures until the plants had five true leaves. During this time, plants were fertilized weekly with $400 \mathrm{~mL}$ of Peters 20N-20P-20K soluble fertilizer (Scotts Sierra, Maryville, Ohio) at a rate of $200 \mathrm{mg} / \mathrm{L}(5 \% \mathrm{~S})$. On 15 Dec. 1997, seedlings were transplanted into $30.5 \times 25.4 \times 8.9$-cm flats containing $50 \%$ Fafard $6 \mathrm{~m}$ media and $50 \%$ washed river sand. Nine seedlings were planted per flat at $7.6 \mathrm{~cm}$ spacing on center. Plants in each flat were fertilized weekly with $1.8 \mathrm{~L}$ of a half-strength modified Hoagland's solution (Hoagland and Arnon, 1950) containing $1 \mathrm{~mm} \mathrm{SO}_{4}^{-2}$ until $\mathrm{SO}_{4}^{-2}$ reduction treatments began. Plants were supplemented with deionized water as needed.

The experimental design was a randomized complete block having four blocks and six $\mathrm{SO}_{4}^{-2}$ reduction treatments per block. There were six flats per block. Starting 26 Jan. 1998, the $\mathrm{SO}_{4}^{-2}$ concentration in the nutrient solution applied to one flat in each block was reduced to $0.05 \mathrm{~mm}$ and maintained at that level until the experiment was terminated. Every two weeks thereafter, another flat in each block received the reduced $\mathrm{SO}_{4}^{-2}$ fertility. A $0.05 \mathrm{~mm}$ $\mathrm{SO}_{4}^{-2}$ concentration was that of the carrier ions of some micronutrients in the Hoagland's solution. The experiment was terminated 13 April 1998 when 50\% of the onions' foliage in the experiment had lodged, indicating matura- 
tion. Six sequential $\mathrm{SO}_{4}^{-2}$ reduction treatments resulted at $77,63,49,35,21$, and $7 \mathrm{~d}$ before harvest, respectively. Developmental stages associated with the sequential reduction dates were nonbulbing plants at $77 \mathrm{~d}$ and $63 \mathrm{~d}$, early bulbing at $49 \mathrm{~d}$, active bulbing at $35 \mathrm{~d}$ and $21 \mathrm{~d}$, and bulb maturation at $7 \mathrm{~d}$ before harvest. Plants were considered to be bulbing when the leaf bases were two times the diameter of the sheath area.

At harvest, a 1-cm cross section of leaves were taken $10 \mathrm{~cm}$ above the bulb for each treatment combination for total $\mathrm{S}$ analysis. The roots and foliage were then removed from the bulbs. The bulbs were dried at ambient greenhouse temperatures for $7 \mathrm{~d}$. The eight most uniform bulbs in each flat were selected for flavor analyses. All analyses were done on the combined tissues of each eight-bulb treatment/block combination. Five-to 10-mm-thick wedges were cut longitudinally from the bulbs. One wedge group was used to determine enzymatically developed pyruvic acid (EPY) and soluble solids content (SSC). EPY and SSC measure gross flavor intensity and sugars, respectively. A second wedge group was used to measure the ACSOs and precursor intermediates, and a third wedge group was used for mineral analysis.

Soluble solids content and gross flavor intensity. Wedges from each eight-bulb group were juiced in a pneumatic press. Several drops of the juice were applied to a hand-held refractometer (Kernco, Tokyo) to measure soluble solids content (SSC). Soluble solids content correlated well with water-soluble carbohydrate content in onions (Mann and Hoyle, 1945). Gross flavor intensity for each treatment combination was determined using the pyruvic acid method of Randle and Bussard (1993). EPY (total pyruvic acid-background pyruvic acid) in the juice was diluted 40 -fold, reacted with 2,4-dinitrophenyl hydrazine, incubated for $10 \mathrm{~min}$ in a $37^{\circ} \mathrm{C}$ water bath, developed with $0.6 \mathrm{~N}$ sodium hydroxide and measured at $420 \mathrm{~nm}$ on a Spectronic 21D spectrophotometer (Milton Roy, Rochester, N.Y.). Pyruvic acid content was calculated against a sodium pyruvate standard curve.

Flavor precursors and precursor intermediates. The ACSOs and their intermediates were extracted twice using a 12 methanol : 3 water solution, and once with an $80 \%$ ethanol solution that was modified for bulb tissue from Lancaster and Kelly (1983). S-Methyl glutathione (MeGTH; $0.5 \mathrm{mg} \cdot \mathrm{g}^{-1}$ fresh weight), g-L-glutamyl-L glutamic acid (ggG; 0.2 $\mathrm{mg} \cdot \mathrm{g}^{-1}$ fresh weight), and ( \pm )-S-1-butyl-L-cysteine sulfoxide (BCSO; $1.0 \mathrm{mg} \cdot \mathrm{g}^{-1}$ fresh weight) were used as internal standards and added to $15 \mathrm{~mL}$ of the combined solutions (1 $\mathrm{g}$ fresh wt. equivalent). The solutions were dried using ambient air and re-dissolved in one $\mathrm{mL}$ of deionized/distilled water. A $0.5-\mathrm{mL}$ aliquot was then subjected to ion exchange chromatography using a $10 \times 40-\mathrm{mm}$ column (Bio-Rad, Hercules, Calif.) with $3 \mathrm{~mL}$ Dowex $1 \times 8$ resin (200 to 400 mesh; Bio-Rad). Fractionation of the sample was carried out using acetic acid at $0.1,0.2,2$, and $5 \mathrm{~m}$ concentrations. The fractions containing the ACSO and the intermediate compounds $(0.1$ and $2 \mathrm{M}$, respectively) were each collected and dried using ambient air. HPLC sample preparation and analysis were done according to Randle et al. (1995). Samples were derivatized using ethanol, triethylamine (TEA), and phenylisothiocyanate, dried and redissolved in $1 \mathrm{~mL}$ of acetonitrile and water before HPLC analysis.

A Waters (Milford, Mass.) 2690 HPLC separator module with a 996 photodiode array detector was used for analysis. A Sphri-5 RP185 micron $250 \times 4.6-\mathrm{mm}$ column (Applied Biosystems, Foster City, Calif.) fitted with a $15 \times 3.2-\mathrm{mm} 7$ micron guard column (RP-18 Newgard; Applied Biosystems) was used for separation. The column temperature was maintained at $30{ }^{\circ} \mathrm{C}$. Eluted compounds were detected at $254 \mathrm{~nm}$. Peak assignment was carried out by comparing retention times with authentic standards (supplied by J.E. Lancaster, Crop and Food Research, Christchurch, New Zealand).

Solvents were A) aqueous acetonitrile $(60 \%)$ and B) $0.14 \mathrm{M}$ sodium acetate with $0.05 \%$ TEA buffered to $\mathrm{pH} 6.35$ using glacial acetic acid. Forty $\mathrm{mL}$ sample volumes were injected onto the column. A flow rate of 1.0 $\mathrm{mL} / \mathrm{min}$ was used. The solvent gradient used was $15 \%$ A for $1.10 \mathrm{~min}, 15 \%$ to $45 \%$ A over $21.1 \mathrm{~min}, 45 \%$ to $100 \% \mathrm{~A}$ over $1 \mathrm{~min}$, and a hold at $100 \%$ A for $14 \mathrm{~min}$.

Sulfur and $\mathrm{SO}_{4}^{-2}$ analysis. Bulb and leaf tissues were dried at $60^{\circ} \mathrm{C}$ in a forced-air oven (model 630; National Appliance Co., Portland, Ore.) for no less than $72 \mathrm{~h}$. The dried tissue was ground through a $0.5-\mathrm{mm}$ screen (Cyclotec, model 1093; Tector, Hoganas, Sweden). Total bulb and leaf S were determined using a Leco $\mathrm{S}$ determinator (model SC 232; St. Joseph, Mich.).

Sulfate concentrations were quantified using anion chromatography. One-half gram of ground bulb tissue was extracted in $100 \mathrm{~mL}$ HPLC grade water for $30 \mathrm{~min}$ with agitation. Ten $\mathrm{mL}$ of the solution were then centrifuged at $7000 \mathrm{rpm}$ for $10 \mathrm{~min}$ (Sorvall, Norwalk, Conn.). The supernatant was filtered through a Millex-GV 0.22- $\mu \mathrm{M}$ filter unit (Millipore, Molsheim, France) and $40 \mu \mathrm{L}$ were injected onto an IC-Pak Anion HR column equipped with a IC-Pak Anion guard pak (Waters, Milford, Mass.). Column temperature was maintained at $30^{\circ} \mathrm{C}$. A Waters (Milford, Mass.) 2690 HPLC separator module with a 432 conductivity detector was used for analysis. A flow rate of $1.0 \mathrm{~mL} \cdot \mathrm{min}^{-1}$ was used with an isocratic sodium borate/gluconate solvent. The solvent contained $16 \mathrm{~g}$ sodium gluconate, $18 \mathrm{~g}$ boric acid, $25 \mathrm{~g}$ sodium tertaborate and 250 $\mathrm{mL}$ glycerin in $1 \mathrm{~L}$ of water. Data were collected and recorded using a personal computer with Millenium chromatography manager software as described earlier. Quantification was performed using $10 \mathrm{mg} \cdot \mathrm{L}^{-1}$ concentrations of the sodium sulfate salt(J.T. Baker, Phillipsburg, N.J.) as an external standard.

Statistical analysis. Data were subjected to analysis of variance and linear and polynomial regression procedures using StatMost software (DataMost, Salt Lake City, Utah). An arcsine transformation of percentage data was done prior to analysis.

\section{Results and Discussion}

Sulfur and $\mathrm{SO}_{4}^{-2}$ accumulation. Leaf and bulb $\mathrm{S}$ responded significantly to the sequential reduction of $\mathrm{SO}_{4}{ }^{-2}$ fertility during plant growth and development $(P=0.01 ; \mathrm{F}=6.1$ and 5.9 , respectively). Leaf $S$ increased linearly as $\mathrm{SO}_{4}^{-2}$ reduction was delayed during growth and development (Leaf $\mathrm{S}=0.523+0.002$ days, $R^{2}=0.93$, Fig. 1). Similarly, bulb $\mathrm{S}$ increased linearly as $\mathrm{SO}_{4}{ }^{-2}$ reduction was delayed (Bulb $\mathrm{S}=0.457+0.002$ days, $R^{2}=0.90$, Fig. 1). Previously, bulb $S$ was shown to change in response to increasing $\mathrm{SO}_{4}^{-2}$ fertility levels (Randle et al., 1999). As $\mathrm{SO}_{4}^{-2}$ fertility increased from 5 to $150 \mathrm{mg} \mathrm{SO}_{4}^{-2}$ per $\mathrm{L}$ of nutrient solution, total bulb S linearly increased in three onion cultivars. Therefore, the response of bulb $\mathrm{S}$ accumulation to prolonging the high $\mathrm{SO}_{4}{ }^{-2}$ fertility regime as plants grew and developed in this study was similar to sequentially increasing the $\mathrm{SO}_{4}^{-2}$ fertility concentrations given throughout growth and development in the previous study.

Bulb $\mathrm{SO}_{4}^{-2}$ accumulation responded significantly to the sequential reduction of $\mathrm{SO}_{4}{ }^{-2}$ fertility $(P=0.007, \mathrm{~F}=5.03)$. Bulb $\mathrm{SO}_{4}^{-2}$ increased linearly as the reduction of $\mathrm{SO}_{4}^{-2}$ fertility was delayed to $7 \mathrm{~d}$ before harvest (Table 1). In a previous study, increasing $\mathrm{SO}_{4}{ }^{-2}$ fertility concentrations corresponded to linear increases in bulb $\mathrm{SO}_{4}{ }^{-2}$ for three onion cultivars (Randle et al., 1999). At low $\mathrm{SO}_{4}^{-2}$ fertility, onions were generally more efficient in metabolizing $\mathrm{SO}_{4}^{-2}$ to organic $\mathrm{S}$ when compared to the $\mathrm{SO}_{4}^{-2}$ metabolism of plants grown at high $\mathrm{SO}_{4}^{-2}$ fertility. As $\mathrm{SO}_{4}{ }^{-2}$ fertility levels increased, bulb $\mathrm{SO}_{4}{ }^{-2}$ began to accumulate, most likely in the vacuole, as an available $\mathrm{S}$ pool (Randle et al., 1999). No trend was found for bulb $\mathrm{SO}_{4}^{-2}$ as a percentage of total bulb $\mathrm{S}$ when $\mathrm{SO}_{4}^{-2}$ fertility was delayed (Table 1).

Soluble solids content and gross flavor intensity. Mature bulb SSC responded significantly to the sequential reduction of $\mathrm{SO}_{4}^{-2}$ during plant growth and development $(P=0.003$; $\mathrm{F}=6.03$ ). There was a decrease in SSC between the $\mathrm{SO}_{4}{ }^{-2}$ reduction 77 days before harvest to 21 days before harvest, followed by an increase in $\mathrm{SSC}$ for the last $\mathrm{SO}_{4}^{-2}$ reduction date (Fig. 2). The overall response of SSC was quadratic $\left(\mathrm{SSC}=7.37-0.0198 \mathrm{~d}+0.0003 \mathrm{~d}^{2}, R^{2}=0.80\right)$. The response of onion SSC to S fertility has been cultivar dependent (Randle, 1992a). When onions of broad genetic background were evaluated at high- and low-S fertility levels, 35 of the entries had higher SSC with the high-S treatment, 25 of the entries had higher SSC with the low-S treatment, and 15 entries had SSC that were unaffected by $\mathrm{S}$ fertility. However, mildtype cultivars, like 'Sweet Vidalia' in our study, generally had higher SSC with low-S fertility compared to plants grown at high-S fertility (Randle and Bussard, 1993). Similarly in our study, reducing $\mathrm{SO}_{4}^{-2}$ early in the bulbing process caused the onions to have higher SSC than those subjected to later $\mathrm{SO}_{4}^{-2}$ reductions, except 


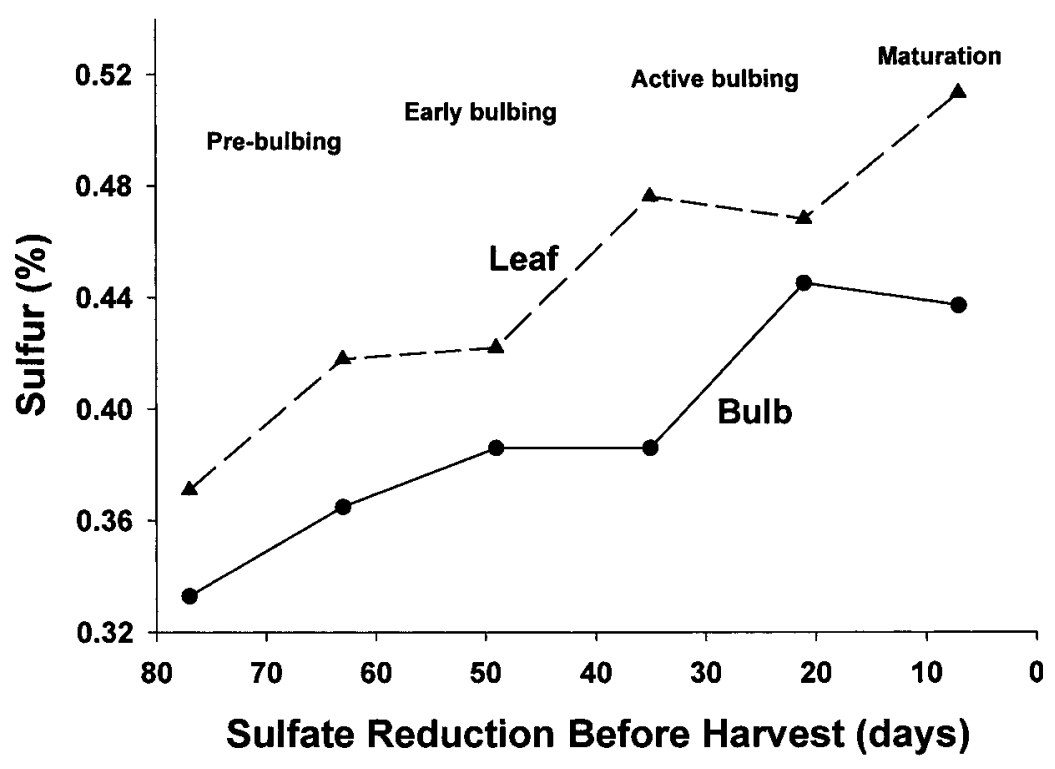

Fig. 1. Changes in total leaf and bulb S from 'Sweet Vidalia' onions when applied $\mathrm{SO}_{4}^{-2}$ concentrations from nutrient solutions were sequentially reduced from $1 \mathrm{~mm}$ to $0.5 \mathrm{~mm}$ at $14-\mathrm{d}$ intervals beginning $77 \mathrm{~d}$ before harvest. Leaf and bulb S increased linearly as $\mathrm{SO}_{4}{ }^{-2}$ reduction was delayed during growth and development (Leaf $\mathrm{S}=0.523-0.002 \mathrm{~d}, R^{2}=0.93$; Bulb S $=0.457-0.002 \mathrm{~d}, R^{2}=0.90$ ).

for the last date. As SSC increased in mild-type onions, greater amounts of sucrose, glucose and fructose accumulated, and these bulbs, therefore, would be perceived sweeter at low-S fertility (Randle and Bussard, 1993). Bulbs subjected to earlier $\mathrm{SO}_{4}^{-2}$ reductions should, therefore, have higher sugars and be perceived sweeter.

Gross flavor intensity, as measured by EPY, responded significantly to the sequential reduction of $\mathrm{SO}_{4}^{-2}$ during plant growth and development $(P=0.01 ; \mathrm{F}=4.43)$. The greater the EPY, the more intense overall onion flavor becomes (Wall and Corgan, 1992). $\mathrm{As} \mathrm{SO}_{4}{ }^{-2}$ reduction was delayed during growth and development, EPY increased linearly $(\mathrm{EPY}=$ $5.18+0.02 \mathrm{~d}, R^{2}=0.86$, Fig. 2). Within the range of EPY concentrations measured in this experiment, a difference of one $\mu \mathrm{mol}$ is perceivable when bulbs are eaten (Randle, 1997). Available $S$ is a primary environmental factor influencing flavor intensity in onions. Increasing $\mathrm{SO}_{4}^{-2}$ concentrations in nutrient solutions linearly increased EPY in three onion cultivars evaluated over five $\mathrm{SO}_{4}^{-2}$ concentrations (Randle et al., 1995). Although a significant positive linear trend was found for EPY in response to delayed $\mathrm{SO}_{4}^{-2}$ fertility reduction, a decrease in EPY was found when $\mathrm{SO}_{4}{ }^{-2}$ was reduced $49 \mathrm{~d}$ before harvest (Fig. 2). Biochemical changes occur early in the bulbing process that prepare the plant for the translocation of metabolites to the leaf bases (Lercari, 1982). It is possible that these metabolic changes affect the synthesis or the composition of the ACSOs more than in previous or subsequent $\mathrm{SO}_{4}^{-2}$ reduction dates. Targeting this developmental stage for $\mathrm{SO}_{4}^{-2}$ fertility reduction may be advantageous in the production of low pungency onions.

Flavor precursors and precursor intermediates. The three ACSOs of onion and the biosynthetic intermediate $\gamma$-glutamyl propenyl cysteine sulfoxide $(\gamma \mathrm{GP})$ responded significantly to the sequential reduction of $\mathrm{SO}_{4}{ }^{-2}$ during plant growth and development. 2-Carboxypropyl glutathione was unaffected by changes in $\mathrm{SO}_{4}^{-2}$ fertility during growth and development. 1-Propenyl cysteine sulfoxide $(P=0.001, \mathrm{~F}=8.34)$ increased linearly as the reduction in $\mathrm{SO}_{4}^{-2}$ concentration was delayed during plant growth and development (1-PRENCSO $=0.735-0.004$ day, $R^{2}=0.95$, Fig. 3 ). The lachrymatory factor is a primary product of the enzymatic decomposition of 1-PRENCSO which also produces organoleptic heat and mouth burn when eaten (Randle, 1997). Therefore, the longer high levels of $\mathrm{SO}_{4}{ }^{-2}$ are made available to the plant during bulbing, the harsher the taste will be when the bulbs are eaten. $\gamma$-Glutamyl propenyl cysteine sulfoxide $(P=0.002, \mathrm{~F}=6.78)$ increased in a cubic response to a delay in the reduction of $\mathrm{SO}_{4}^{-2}$ during growth and development $\left(\gamma \mathrm{GP}=1.054-0.025 \mathrm{~d}+0.0005 \mathrm{~d}^{2}-\right.$ 4.13 day $^{3}, R^{2}=0.96$, Fig. 3). $\gamma$-Glutamyl propenyl cysteine sulfoxide is the penultimate peptide in the synthesis of 1-PRENCSO. $\gamma \mathrm{GP}$ was generally found in higher concentrations than 1-PRENCSO. Recent evidence from our laboratory suggests that when onions are juiced, between 30 and $50 \%$ of the $\gamma \mathrm{GP}$ is degraded to 1-PRENCSO in the macerate. Evidence suggests that some of the $\gamma \mathrm{GP}$ is converted to 1-PRENCSO and is then hydrolyzed to form the lachrymatory factor (unpublished data). Increasing $\gamma$ GP concentrations in response to delayed $\mathrm{SO}_{4}^{-2}$ reduction could contribute to 1-PRENCSO concentrations and, therefore, affect the harshness of these onions. During bulb storage, $\gamma \mathrm{GP}$ was also shown to be systematically converted to 1-PRENCSO in Granex-type onions (Kopsell et al., 1999), which lead to increases in over-
Table 1. Bulb $\mathrm{SO}_{4}^{-2}(\%)$ and $\mathrm{SO}_{4}^{-2}$ as a percentage of total bulb $\mathrm{S}$ in 'Sweet Vidalia' onions when $\mathrm{SO}_{4}^{-2}$ fertility was sequentially reduced at 14-d intervals beginning $77 \mathrm{~d}$ before harvest. Bulb $\mathrm{SO}_{4}^{-2}=6.5-0.03 \mathrm{~d} ; R^{2}=0.86$.

\begin{tabular}{lcc}
\hline $\begin{array}{l}\mathrm{SO}_{4}^{-2} \text { Reduction } \\
(\mathrm{d})\end{array}$ & $\begin{array}{c}\mathrm{Bulb} \mathrm{SO}_{4}^{-2} \\
(\% \text { dry wt })\end{array}$ & $\begin{array}{c}\mathrm{S}^{-2} \mathrm{SO}_{4}^{-2} \\
(\%)\end{array}$ \\
\hline 77 & 0.043 & 12.9 \\
63 & 0.049 & 13.4 \\
49 & 0.046 & 12.0 \\
35 & 0.058 & 15.1 \\
21 & 0.061 & 13.7 \\
7 & 0.061 & 14.0 \\
\hline
\end{tabular}

all flavor intensity during storage (Kopsell and Randle, 1997). Delaying $\mathrm{SO}_{4}^{-2}$ reduction should cause Granex-type onions to not only be harsh when eaten at harvest, but to also become even harsher during storage as $\gamma \mathrm{GP}$ is converted to 1-PRENCSO.

In a quadratic response to delayed $\mathrm{SO}_{4}^{-2}$ reduction during growth and development, $\operatorname{MCSO}(P=0.05, \mathrm{~F}=2.89)$ decreased as plants went through pre-bulbing into active bulbing, and then increased as bulbs matured ( $\mathrm{MCSO}=$ $1.19-0.016$ day +0.0002 day $^{2}, R^{2}=0.88$, Fig. $3)$. Methyl cysteine sulfoxide accumulated in highest concentration of the three ACSOs measured. Thiosulfinates from the enzymatic decomposition of MCSO produce fresh onion and cabbage-like flavors when the bulbs are eaten. Although PCSO was significant in response to the sequential reduction of $\mathrm{SO}_{4}{ }^{-2}$ $(P=0.003, \mathrm{~F}=5.93)$, the levels measured were very low (Fig. 3). The response followed a cubic trend $(\mathrm{PCSO}=0.084-0.0018 \mathrm{~d}+$ $0.0006 \mathrm{~d}^{2}-0.0001 \mathrm{~d}^{3}, R^{2}=0.92$ ). Thiosulfinates from the decomposition of PCSO give rise to raw, fresh onion-like flavors (Randle, 1997).

Because the decomposition products from 1-PRENCSO can dominate the organoleptic experience, 1-PRENCSO must be in low enough concentrations for sugars to be perceived over the heat and mouth burn. As the high $\mathrm{SO}_{4}^{-2}$ solution concentrations were provided closer to harvest, 1-PRENCSO accumulated in higher concentration while MCSO and SSC decreased in concentration. These onions would be harsher and perceived less sweet. Conversely, onions exposed to early $\mathrm{SO}_{4}^{-2}$ reductions should be perceived sweeter because of higher SSC and lower 1-PRENCSO concentrations. Typically, storage-type onions have higher SSC than mild sweet onions. However, storage onions are typically more pungent and the sugars are not perceived when eaten raw (Randle, 1992b, personal experience). As $\mathrm{SO}_{4}^{-2}$ reduction occurred earlier in growth and development, the response of the ACSOs were similar to what was found in a previous study when $\mathrm{SO}_{4}^{-2}$ concentrations were given at consistent levels through out the growing season (Randle, et al., 1995). In that study, luxuriant $\mathrm{SO}_{4}^{-2}$ fertility concentrations resulted in high 1-PRENCSO concentrations, and low PCSO and MCSO concentrations. Conversely, low to deficient $\mathrm{SO}_{4}^{-2}$ fertility levels resulted in lower 1-PRENCSO and higher PCSO and MCSO concentrations. 


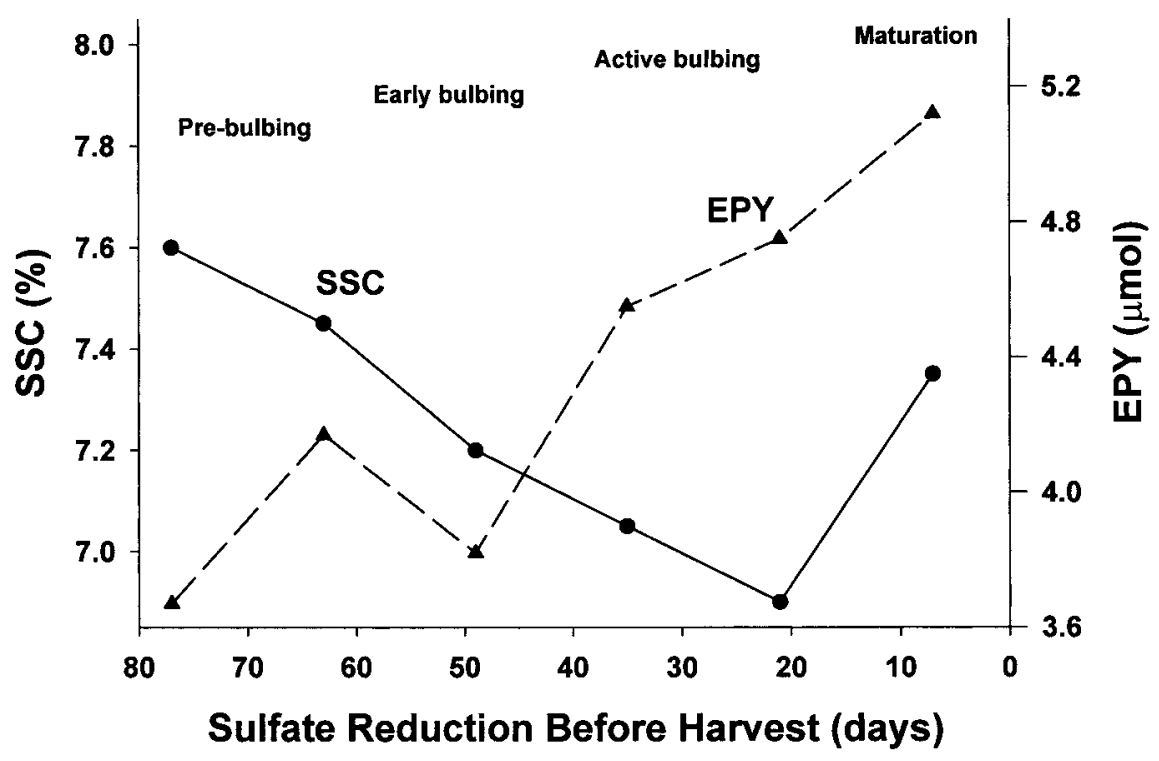

Fig. 2. Changes in soluble solids content (SSC) and enzymatically developed pyruvate (EPY) concentration from mature 'Sweet Vidalia' bulbs when applied $\mathrm{SO}_{4}^{-2}$ concentrations from nutrient solutions were sequentially reduced from $1 \mathrm{~mm}$ to $0.5 \mathrm{~mm}$ at 14-d intervals beginning $77 \mathrm{~d}$ before harvest. Soluble solids content decreased quadratically ( $\mathrm{SSC}=7.37-0.0198 \mathrm{~d}+0.0003 \mathrm{~d}^{2}, R^{2}=0.80$ ), and EPY increased linearly $\left(\mathrm{EPY}=5.18+0.02 \mathrm{~d}, R^{2}=0.86\right)$ in response to decreasing $\mathrm{SO}_{4}^{-2}$ concentrations.

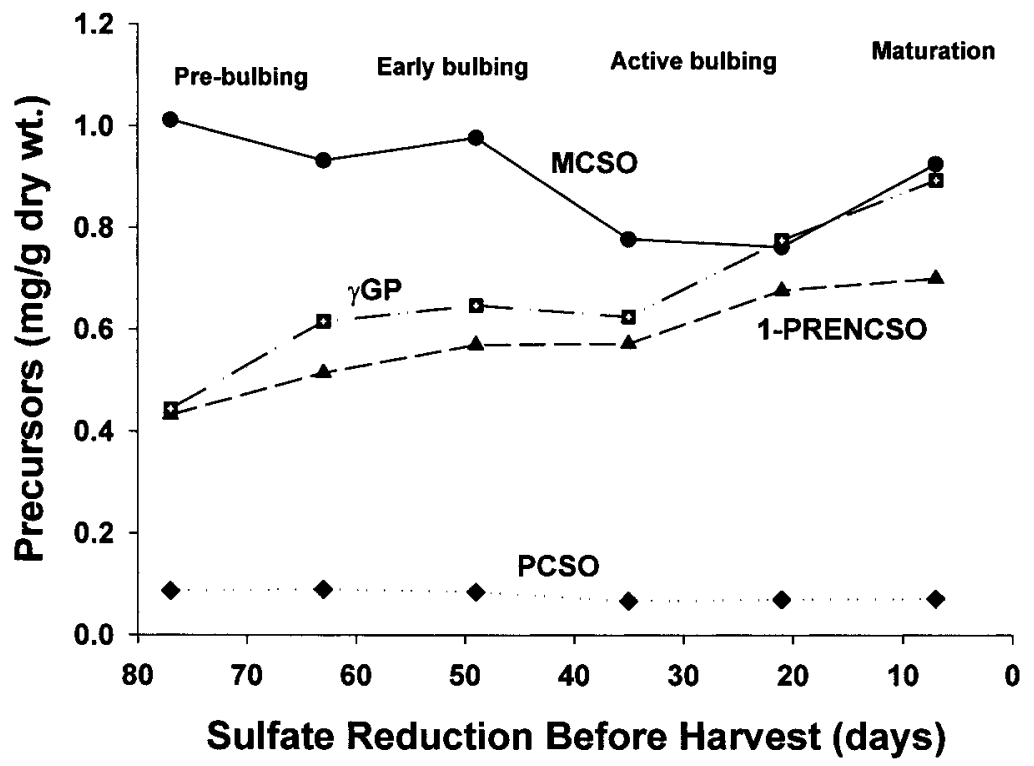

Fig. 3. Changes in methyl cysteine sulfoxide (MCSO), 1-propenyl cysteine sulfoxide (1-PRENCSO), propyl cysteine sulfoxide (PCSO), and $\gamma$-glutamyl cysteine sulfoxide $(\gamma \mathrm{GP})$ from mature 'Sweet Vidalia' bulbs when applied $\mathrm{SO}_{4}{ }^{-2}$ concentrations from nutrient solutions were sequentially reduced from $1 \mathrm{~mm}$ to 0.5 $\mathrm{mm}$ at 14-d intervals beginning $77 \mathrm{~d}$ before harvest. The response of MCSO to decreasing $\mathrm{SO}_{4}{ }^{-2}$ concentrations was quadratic (MCSO $\left.=1.19-0.016 \mathrm{~d}+0.0002 \mathrm{~d}^{2}, R^{2}=0.88\right)$, while 1-PRENCSO was linear $\left(1-\mathrm{PRENCSO}=0.735-0.004 \mathrm{~d}, R^{2}=0.95\right), \mathrm{PCSO}$ was cubic $(\mathrm{PCSO}=0.084-0.0018 \mathrm{~d}+0.0006$ $\left.\mathrm{d}^{2}-0.0001 \mathrm{~d}^{3}, R^{2}=0.92\right)$ and $\gamma \mathrm{GP}$ was cubic $\left(\gamma \mathrm{GP}=1.054-0.025 \mathrm{~d}+0.0005 \mathrm{~d}^{2}-4.13 \mathrm{~d}^{3}, R^{2}=0.96\right)$.

The significant linear increases in EPY, $\gamma \mathrm{GP}$, and 1-PRENCSO with delaying $\mathrm{SO}_{4}^{-2}$ reduction suggest that $\mathrm{SO}_{4}^{-2}$ should be reduced as early as possible for mild sweet onion production. However, restricting $\mathrm{SO}_{4}^{-2}$ too early adversely impacts bulb fresh weight (Randle et al., 1995). A potential target date for $\mathrm{SO}_{4}^{-2}$ reduction could be a time $\approx 7$ weeks prior to harvest that coincides with the onset of bulbing. Changes that occurred in the flavor biosynthetic pathway during this time could be associated with the metabolic changes that decrease in soluble solids that was associated with later $\mathrm{SO}_{4}^{-2}$ reductions. Lower SSC would be associated with decreasing sugar content in the bulbs.

\section{Literature Cited}

Block, E. 1992. Organosulfur chemistry of the genus Allium-Implications for the organic chemistry of sulfur. Agnew. Chem. Int. Ed. Engl. 31:11351178.

Brewster, J.L. 1990. Cultural systems and agronomic practices in temperate climates, p. 1-30. In: H.D. Rabinowitch and J.L. Brewster (eds.). Onions and allied crops. vol. 2. CRC Press, Boca Raton, Fla.

Kopsell, D.A. and W.M. Randle. 1999. Selenium affects the S-alk(en)yl cysteine sulfoxides among short-day onion cultivars. J. Amer. Soc. Hort. Sci. 124:307-311.

Kopsell, D.E. and W.M. Randle. 1997. Onion cultivars differ in pungency and bulb quality changes during storage. HortScience. 32:1260-1263.

Kopsell, D.E., W.M. Randle, and M.A. Eiteman. 1999. Changes in the S-alk(en)yl cysteine sulfoxides and their biosynthetic intermediates during onion storage. J. Amer. Soc. Hort. Sci. 124:177183.

Lancaster, J.E. and M.J. Boland. 1990. Flavor biochemistry, p. 33-72. In: H.D. Rabinowitch and J.L. Brewster (eds.). Onions and allied crops. vol. 3. CRC Press, Boca Raton, Fla.

Lercari, B. 1982. Changes in invertase activities during the photoperiodically induced bulb formation of onion (Allium cepa L.) Physiol. Plant., 54:480-487.

Mann, L.K. and E.J. Hoyle. 1945. Use of the refractometer for selecting onion bulbs high in dry matter for breeding. Proc. Amer. Soc. Hort. Sci. 46:285-292.

Randle, W.M. 1992a. Sulfur nutrition affects nonstructural water-soluble carbohydrates in onion germplasm. HortScience. 27:52-55.

Randle, W.M. 1992b. Onion germplasm interacts with sulfur fertility for plant sulfur utilization and bulb pungency. Euphytica 59:151-156.

Randle, W.M. 1997. Onion flavor chemistry and factors influencing flavor intensity, p. 41-52. In: S.J. Risch and C. Ho (eds.). Spices: Flavor chemistry and antioxidant properties. ACS Symposium Series 660, Washington, D.C.

Randle, W.M. 2000. Increasing nitrogen concentration in hydroponic solutions affects onion flavor and bulbquality. J. Amer. Soc. Hort. Sci. 125:254 259.

Randle, W.M., M.L. Bussard, and D.F. Warnock. 1993. Ontogeny and sulfur fertility affect leaf sulfur in short-day onions. J. Amer. Soc. Hort. Sci. 118:762-765.

Randle, W.M., D.E. Kopsell, D.A. Kopsell, and R.L. Snyder. 1999. Total sulfur and sulfate accumulation in onion is affected by sulfur fertility. J. Plant Nutr. 22:45-51.

Randle, W.M., J.E. Lancaster, M.L. Shaw, K.H. Sutton, R.L. Hay, and M.L. Bussard. 1995. Quantifying onion flavor compounds responding to sulfur fertility-sulfur increases levels of alk(en)yl cysteine sulfoxides and biosynthetic intermediates. J. Amer. Soc. Hort. Sci. 120:1075-1081.

Smittle, D.A. 1984. Responses of onions to sulfur and nitrogen fertilization. Georgia Agr. Expt. Stn. Res. Rpt. 455.

Vavrina, C.S. and D. Granberry. 1988. Dry bulb onions. Univ. Georgia Ext. Circ. 801.

Wall, M.M. and J.N. Corgan. 1992. Relationship between pyruvate analysis and flavor perception for onion pungency determination. HortScience 27:1029-1030. 